\title{
Immobilization of two endoglucanases from different sources
}

\author{
Rosalba Sarcina ${ }^{1}$, Concetta Valeria L. Giosafatto ${ }^{1}$, Vincenza Faraco ${ }^{1}$, Licia Lama ${ }^{2}$, \\ Marilena Esposito ${ }^{1}$, Loredana Mariniello ${ }^{1}$
}

\author{
${ }^{1}$ Department of Chemical Sciences, University of Naples 'Federico II", Complesso Universitario Monte Sant'Angelo, via \\ Cinthia 4, 80126 Naples, Italy \\ ${ }^{2}$ ICB-CNR, via Campi Flegrei 34 80078, Pozzuoli, Naples, Italy
}

\begin{abstract}
Cellulases are a important family of hydrolytic enzymes which catalyze the bond of cellulose and other related cello-oligosaccharide derivates. Industrial applications require enzymes highly stable and economically viable in terms of reusability. These costs can be reduced by immobilizing the cellulases, offering a potential solution through enzyme recycling and easy recovery. The covalent immobilization of enzymes is reported here: one is commercial cellulase from Aspergillus niger and other one is recombinant enzyme, named CelStrep it because was isolated from a new cellulolytic strain, Streptomyces sp. G12,. The optimal pH for binding is 4.6 for both cellulases and the optimal enzyme concentrations are $1 \mathrm{mg} / \mathrm{mL}$ and $5 \mathrm{mg} / \mathrm{mL}$ respectively. The support for immobilization is a poliacrylic matrix. Experiments carried out in this work show positive results of enzyme immobilization in terms of efficiency and stability and confirm the economic and biotechnical advantages of enzyme immobilization for a wide range of industrial applications.
\end{abstract}

Keywords - Aspergillus. niger, endoglucanases, immobilization, Streptomyces.

\section{INTRODUCTION}

Cellulases (E.C. 3.2.1.-) are enzymes that hydrolyze $\beta$ 1,4 glycosidic bonds in cellulose. Namely, they can be distinguished in endoglucanases (E.C. 3.2.1.4), exoglucanases (E.C.3.2.1.91) and $\beta$-glucosidases (E.C.3.2.1.21). They are mainly used in various industries including pulp and paper, textile, laundry, food and feed industry, brewing, and agriculture [1]. They are important also for the production of biofuel, for which there is an important demand to have a more sustainable life style worldwide. However, biomass refineries are not spread out in the world because the cost of cellulase highly affects the production of cellulosic-derived ethanol. To overcome this problem many researches are dedicated to both find new cellulases and also produce immobilized enzymes to make more inexpensive biofuel production. Cellulases are enzymes synthesized by a variety of microorganisms: bacteria and fungi (yeasts and molds) during their growth on cellulosic materials [2][3]. From the structure point of view, all of them contain a catalytic domain (Glycoside Hydrolase, GH) that can/may be linked through a simple sequence to a Carbohydrate Binding Domain (CBD) o Module (CBM). The catalytic domain is recognized as a Concanavalin-like domain that is common in both bacterial and fungal cellulases, while the CBD is present mostly in bacterial cellulases. Some bacteria possess "cellulosomes", cellulase complexes with both type of enzymes (with and without the CBD). In this work we have used two different endoglucanases. The first one is the commercial cellulase from the fungus Aspergillus niger (A. niger), that possesses only the Concanavalin-like domain, while the second one is a recombinant protein isolated from a new cellulolytic bacterial strain, identified as belonging to Streptomyces sp. G12, isolated from mature compost obtained from agro-industrial wastes and named CelStrep by the authors [4]. Thus, the aim of this work was to immobilize both $A$. niger and Cel Strep cellulases and examine the activity of immobilized enzymes. In fact, enzyme immobilization provides the advantage of both re-use and increased enzyme stability and, consequently, reducing costs of specific industrial process (E. Cherian et al., 2015), i.d. biofuel production. The used covalent immobilization method recurs to Immobeads, namely COV-2 (150P), that have a polyacrylic matrix bringing an high amount of epoxide groups which bind the thiol, amine and hydroxyl groups of enzymes [5]. Furthermore we have studied the stability of the immobilized enzymes over the time.

\section{MATERIALS AND METHODS}

\section{Materials}

The supports used for immobilization process were Immobeads IB-COV-2-150P, (ChiralVision B.V., The Netherlands). Two different Cellulases (EC 3.2.1.4 - 1,4$\beta$-endoglucanase) were used : the first from Aspergillus niger (A. niger, purchased by Sigma Aldrich - USA), and the second, a recombinant enzyme named CelStrep (Amore et al. 2012). A. niger cellulase activity was determined by using a kit purchased from Megazyme 
(Megazyme International Ireland) using AZO-CMcellulose. CelStrep activity was determined according to Ghose (1987)[6] using 3.5-dinitrosalicylic acid (DNSA) purchased from Merck. Sodium acetate trihydrate, zinc acetate and other reagents were purchased from Sigma Aldrich (USA).

\section{Methods}

\section{Immobilization procedure}

The cellulases were covalently linked to epoxy groups on the beads (IB-COV-2-150P). These were equilibrated with sodium acetate buffer $(0.1 \mathrm{M} \mathrm{pH} 6.2) .400 \mu \mathrm{L}$ of 1 $\mathrm{mg} / \mathrm{mL}$ enzyme solution from $A$. niger and $400 \mu \mathrm{L}$ of 5 $\mathrm{mg} / \mathrm{mL}$ enzyme solution from Celstrep were added to $100 \mathrm{mg}$ of beads, in $2 \mathrm{~mL}$ vials and suspended in sodium acetate buffer (0.1 M, pH 4.6).

The beads-enzyme mixture was shacked for $3 \mathrm{~h}$ at $4{ }^{\circ} \mathrm{C}$ on the rotary mixer to allow the reaction. After that, the vials were let stand overnight at $4^{\circ} \mathrm{C}$ in order to promote the natural decantation of the beads.

Then the supernatants were removed from the sedimented beads and used to determine enzyme activity. Finally beads were washed on the rotary mixer four times with $1.5 \mathrm{~mL}$ sodium acetate buffer ( $0.1 \mathrm{M} \mathrm{pH} 4.6)$ : first wash was performed for $1 \mathrm{~min}$; second and third washes for 15 min; fourth wash for $5 \mathrm{~min}$. The amount of immobilized and active enzyme $\left(\mathrm{U}_{\mathrm{S}}\right)$ was determined by subtracting enzyme activity resolved in supernatants and washes $\left(U_{f}\right)$ from the total enzymatic activity before immobilization $\left(\mathrm{U}_{0}\right)$.

\section{Endoglucanase Assay using Megazyme kit}

The enzymatic activity of free or immobilized endoglucanase from A. niger was measured using AZOCM-Cellulose as a substrate according to the supplier instructions (Megazyme).

\section{Endoglucanase Assay using DNSA}

The enzymatic activity of free or immobilized endoglucanase Celstrep was measured using the 3.5dinitrosalicylic acid based method (DNSA) [6].

\section{Determination of protein concentration}

Protein determination was carried out by the Bio-Rad Protein Assay (Bio-Rad), using bovine serum albumin as standard [7].

\section{Calculation of the parameters of immobilization}

The calculation of the parameters of immobilization and immobilized protein were calculated as follows according to R.A. Sheldon et al. [8].

Immobilized Protein Yield (IPY)(also defined as Protein Loading) - percentage of immobilized protein based on difference of proteins subjected to immobilization $\left(\mathrm{P}_{0}\right)$ and the proteins remaining in residual liquid after immobilization $\left(\mathrm{P}_{\mathrm{f}}\right)$, divided by $\mathrm{P}_{0}$ according to eq. 1 .

$I P Y(\%)=\left[\left(P_{0}-P_{f}\right) / P_{0}\right] \times 100(e q .1)$

Enzyme Immobilization Yield (IY) - percentage of immobilized enzyme based on the difference of enzyme subjected to immobilization $\left(\mathrm{U}_{0}\right)$ and that one remained in the liquid after the immobilization $\left(\mathrm{U}_{\mathrm{f}}\right)$ divided by enzyme subjected to immobilization $\mathrm{U}_{0}$ according to the eq. 2.

$I Y(\%)=\left[\left(U_{0}-U_{f}\right) / U_{0}\right] \times 100($ eq. 2$)$

Activity Recovery (AR) - percentage of immobilized enzyme in the support (Us) divided by $\mathrm{U}_{0}$ according to the eq 3. AR represents the percentage of active immobilized enzyme over the total enzyme subjected to immobilization.

$A R(\%)=\left[U_{S} / U_{0}\right] \times 100($ eq.3)

Lost Activity (LA) - percentage of the lost enzymes in the total immobilization process, due to the difference of $U_{0}$ and the sum of $U_{S}$ and $U_{f}$, according to the eq. 4 .

$L A(\%)=\left[\left(U_{0}-\left(\right.\right.\right.$ Usupport $\left.\left.\left.+U_{f}\right)\right) / U_{0}\right] \times 100($ eq. 4$)$

Efficiency (E) also named Recovered Activity (RA) percentage of immobilized enzyme in the support $\left(U_{S}\right)$ divided by the difference between $\mathrm{U}_{0}$ and $\mathrm{U}_{\mathrm{f}}$, according to the eq. 5.

$\mathrm{E}(\%)=\left[\left(U_{\mathrm{S}}\right) /\left(U_{0}-U_{f}\right)\right] \times 100($ eq. 5$)$

The efficiency can be considered more precise immobilization yield than IY since the first is based on the enzyme activity measured in the support (immobilized enzymes). There is a loss of activity in the immobilized enzyme, or not all enzymes remain active in the support.

\section{Stability of immobilized enzyme}

The stability of immobilized enzyme was monitored over the time, from time 0 (immobilization day) until 45 days after immobilization, using Efficiency parameter as equal to $100 \%$ of cellulase activity at time 0 . The immobilized enzymes were stored at $4^{\circ} \mathrm{C}$.

\section{Analysis of protein sequences}

Information on the sequences and domain composition of A. niger and of Streptomyces cellulase has been taken from UniProt database (codes A2R322_ASPNC and I7L8N7_9ATCN, respectively) [9]. 


\section{RESULTS AND DISCUSSION}

In this study we have covalently immobilized two different cellulases, the first one from the mold A. niger commercialized from Sigma while, the second is a recombinant form previously cloned from a the cellulolytic strain Streptomyces sp. G12 isolated from compost [4]. The immobilization procedure has been realized using the same protocol reported in Fig. 1. The support for immobilizazion are beads made of a polyacrilic matrix with epoxide groups that promote covalent binding to amino, thiol or hydroxyl groups of the enzyme. In Table 1 are reported immobilization parameters obtained with the two different enzymes. Immobilization Yield, calculated as reported in M\&M, is approximately the same for both enzimes, reaching $67 \%$ for A. niger and $55 \%$ for CellStrep. This parameter is calculated measuring U0 and Uf, without taking into account whether the enzyme molecules that have been bound to the support are all active. The last information is given from the Activity Recovery which is calculated as a ratio between the enzyme bound to the support (US) and the Enzyme subjected to immobilization $\left(\mathrm{U}_{0}\right)$. This parameter is equal to $53 \%$ for A.niger and to $13 \%$ for CellStrep. Conversely the Lost Activity is $14 \%$ for the first cellulase and $42 \%$ for the second one. Efficiency, which represents the percentage of the funtional immobilized enzyme over the total (funcional and not funcional) immobilized enzyme is $78 \%$ for A.niger and $23 \%$ for CelStrep, while the Immobilization Protein Yield (also know as Protein loading) is equal to $42 \%$ for A. niger and $70 \%$ for CelStrep. These results could be related to both molecular weight and sequence of the two different enzymes. In fact, fungal cellulase is smaller (26 $\mathrm{kDa}$ ) than the bacterial one (which is $37 \mathrm{kDa}$ ). In fact, $A$. niger cellulase contains only the Concavalin-like Domain, while the Carbohydrate Binding Domain is missing. The Concanvalin-like Domain contains 113 residues out of 223 that possesses amino, thiol and hydroxyl groups, the ones classified as polar amino acids that are able to bing the epoxide groups of the Immo-beads 150P which represent $50.64 \%$ of the entire amino acid sequence (Table 2). On the contrary, the CelStrep contains both Cocanavali-like Domain and carbohydrate Binding Domain that are made of 228 and and 103 amino respectively, among which polar residues represent 45.13 and $39.78 \%$ (Table 2). Thus, the latter enzyme exhibits an higher protein loading but a lower efficiency because most probably more residues are involved in the covalent binding to the support influencing enzyme functionality. In fact, it has been reported that high epoxide group content (tipycal of the Immo-beads 150P) provides quick binding but also multi-point attachment that is detrimental for some enzymes [5]. On the contrary for A. niger, even if the IPL is lower, the covalent binding occurs involving residues without effecting the terziary structure and thus the enzymatic activity. Similar results have been described in studies devoted to assess the immobilizazion efficiency in regard to the protein size [5]. In terms of stability, both immobilized endocellulases retained $100 \%$ activity after 45 days compared to the free enzymes (Fig. 2). In fact, A. niger lost $20 \%$ of its activity, while CelStrep exhibited only $60 \%$ of activity compared to the immobilized enzyme. The higher stability over the time of the free $A$. niger cellulase is not suprising since it is well know that fungal enzymes are usually more stable than bacterial ones [10].

\section{CONCLUSIONS}

This study compares the activity of immobilized endocellulases of different origin. While A. niger endocellulase has been already immobilized by Huang et al 2014 [11], CelStrep was immobilized for the first time. The paper by Huang et al (2014)[11] refers of A. niger immobilized by recurring to magnetic nanoparticles that allow a re-use of the enzyme during idrolization of rice straw to produce ethanol. The process was judged efficient even if the immobilized enzyme only retained $80 \%$ of activity compared to the free one. CelStrep is a bacterial endocellulase isolated from a cellulolitic strain present in agro-industrial waste-derived compost by Amore et al 2012 [4] with the aim of selecting effective enzyme to treat cellulosic materials. Both endocellulases were immobilized on a polar polyacrilic matrix, previously used successfully in our laboratories to immobilize aspartic protease from Carduus defloratus [12], and retained the same activity compared to the free counterparts. Moreover, both enzymes exhibit a good stability over the time while, between the two different free enzymes, the A.niger cellulase retains $80 \%$ activity after 45 days, although CelStrep was $60 \%$ active in respect to the activity at time 0 .

\section{ACKNOWLEDGEMENTS}

This study was supported by grant from the Ministero dell'Università e della Ricerca Scientifica Industrial Research Project B Development of green technologies for production of BIOchemicals and their use in preparation and industrial application of POLImeric materials from agricultural biomasses cultivated in a sustainable way in Campania region-BioPoliS PON03PE_00107_1/1, funded in the frame of Operative National Programme Research and Competitiveness 2007-2013. We are grateful to Maria Fenderico for technical assistance and to Prof. Anna Marabotti for helpful discussion on sequences of cellulases. 


\section{REFERENCES}

[1] Kuhad, R.C., Gupta, R., and Singh, A. (2011). Microbial Cellulases and Their Industrial Applications. Enzyme Research, 2010: 10 pages, Article ID 280696, doi:10.4061/2011/280696.

[2] Kubicek, C.P., Messner, R., Gruber, F., Mandelss, M. and Kubicek-Pranz, E.M. (1993). Triggering of Cellulase Biosynthesis by Cellulose in Trichoderma reesei. The Journal of Biological Chemistry, v 268(26):19364-19368.

[3] Sang-Mok, L. and Koo, Y-M. (2001). Pilot-scale production of cellulase using Trichoderma reesei Rut C-30 in fedbatch mode. Journal of Microbiology and Biotechnology, 11(2):229-233.

[4] Amore, A., Pepe, O., Ventorino, V., Birolo, L., Giangrande, C., Faraco, V. (2012). Cloning and recombinant expression of a cellulase from the cellolytic strain Streptomyces sp. G12 isolated from compost. , 26;11:164.

[5] Mateo, C., Grazu, V., and Guisan, J.M.Guisan, J.M. (2013). Immobilization of Enzymes on monofunctional and heterofunctional epoxyactivated supports in Guisan, J.M.(ed.) Immobilization of Enzymes and Cells: Third edition. Methods in Molecular Biology. Springer Science+Business Media, New York,1051:43-57.

[6] Ghose, T.K. (1987). Measurement of cellulase activities. Pure \& Applied Chemistry, 59:257-268.
[7] Bradford, M. (1976). A Rapid and Sensitive Method for the Quantitation of Microgram Quantities of Protein Utilizing the Principle of Protein-Dye Binding. Analytical Biochemistry, 72:248-254.

[8] Sheldon, R.A. and van Pelt, S. (2013). Enzyme Immobilisation in biocatalysis: why, what and how. The Royal Society of Chemistry,42:6223-6235.

[9] The UniProt Consortium. UniProt: the universal protein knowledgebase.(2017) Nucleic Acids Research, 45: D158-D169 (2017)].

[10] Polaina, J. and A. P. MacCabe, A.P. editors (2007). Industrial Enzymes Structure, Function and Applications Springer, The Netherlands.

[11]Huang, P.J., Chang, K.L., Hsieh, J.F. and Chen, S.T. (2014) Catalysis of rice straw hydrolysis by the combination of immobilized Cellulase from Aspergillus niger on $\beta$-cyclodextrin- $\mathrm{Fe}_{3} \mathrm{O}_{4}$ nanoparticles and ionic liquid". BioMed Research International 2015:9 pages, Article ID 409103, doi:10.1155/2015/409103

[12]Esposito, M., Di Pierro, P., Dejonghe, W., Mariniello, L. and Porta, R. (2016). Enzymatic milk clotting activity in artichoke (Cynara scolymus) leaves and alpine thistle (Carduus defloratus) flowers. Immobilization of alpine thistle aspartic protease". Food Chemistry, 204:115-121.

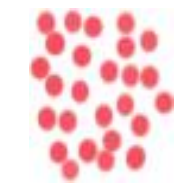

Support for immobilizzation

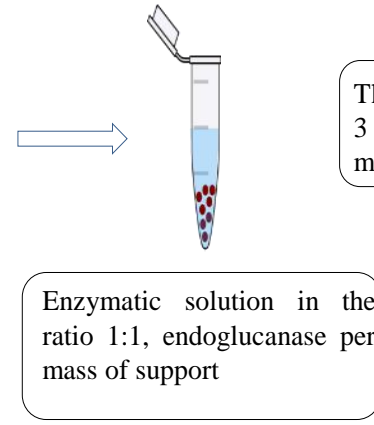

The beads were kept at $4 \mathrm{C}$ for

$3 \mathrm{~h}$ under agitation and then for more 12 hour without agitation

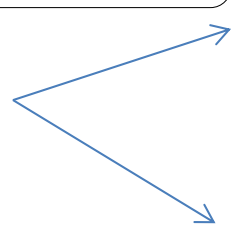

After this step, the solid phase was separated from the liquid, for use in tests of enzymatic activity

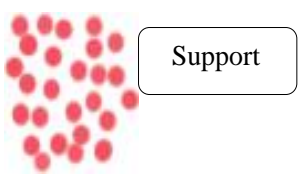

Calculation of the parameters

Residual liquid after immobilization

Fig.1: Flowchart of the enzyme immobilization process

Table.1: Parameters of immobilized cellulases

\begin{tabular}{llllll}
\hline & IY & AR & LA & E & IPY \\
$(\boldsymbol{\%})$ & $(\boldsymbol{\%})$ & $(\%)$ & $78 \pm 6.22$ & $42.57 \pm 5.07$ \\
\hline $\begin{array}{l}\text { Aspergillus } \\
\text { niger }\end{array}$ & $67.01 \pm 3.78$ & $53.57 \pm 4.23$ & $14.28 \pm 1.89$ & $78 \pm$
\end{tabular}




\section{CelStrep}

$55.44 \pm 3.63$

$13.04 \pm 5.11$

$42.41 \pm 1.45$

$23.23 \pm 7.69$

$70.41 \pm 5.76$

Table.2: Percentage of polar amino acids (aa) in each domain of the studied endocellulases

\section{ConA-like Domain CB Domain Total number of aa}

\begin{tabular}{cccc}
\hline Aspergillus niger & 223 aa & - & 223 aa \\
\% of polar aa & 50.64 & - & 50.64 \\
CelStrep & 228 aa & $103 \mathrm{aa}$ & 331 aa \\
\% of polar aa & 45.13 & 39.78 & 43.5 \\
\hline
\end{tabular}

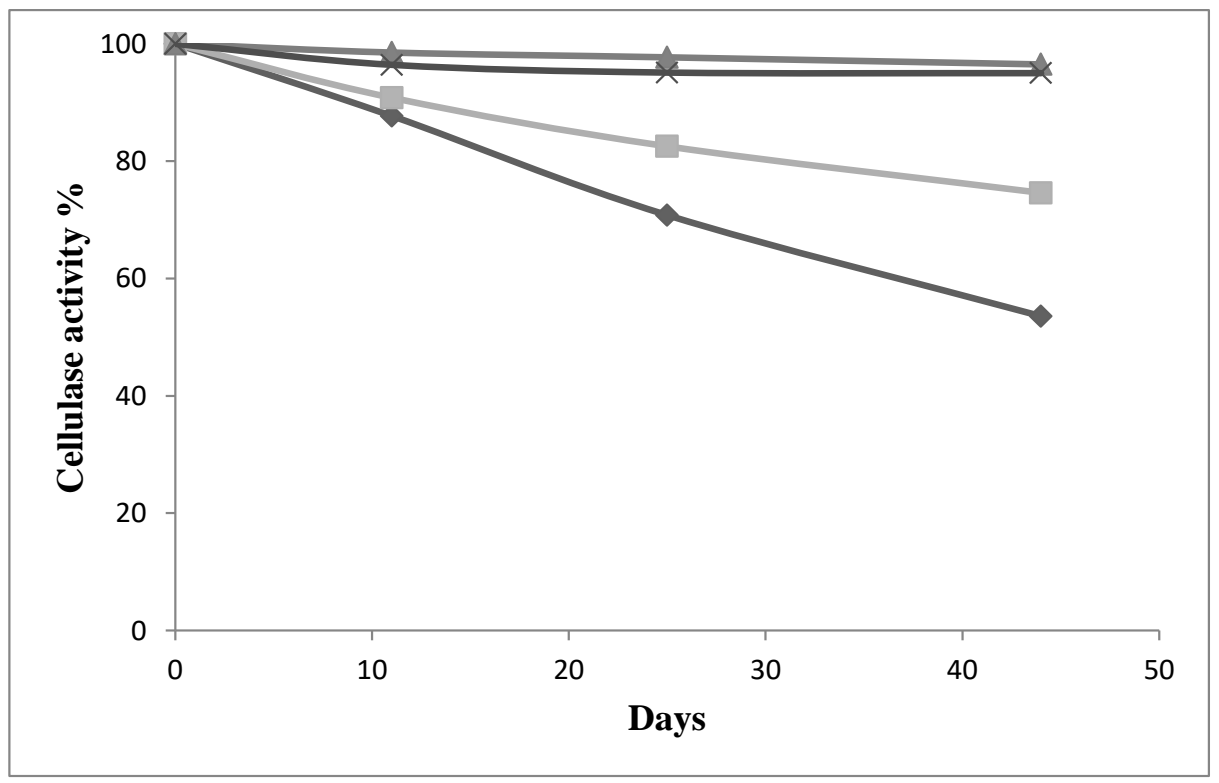

Fig.2: Stability of immobilized cellulases from Aspergillus niger $(\times)$ and Celstrep (\) and of free enzymes, Celstrep ( $)$ and A.niger (-) during storage $\left(\right.$ at $\left.4^{\circ} \mathrm{C}\right)$ 